\title{
Impact of pulmonary rehabilitation on quality of life and functional capacity in patients on waiting lists for lung transplantation*
}

\author{
Impacto da reabilitação pulmonar na qualidade de vida e na capacidade \\ funcional de pacientes em lista de espera para transplante pulmonar \\ Juliessa Florian, Adalberto Rubin, Rita Mattiello, Fabrício Farias da Fontoura, \\ José de Jesus Peixoto Camargo, Paulo Jose Zimermann Teixeira
}

\begin{abstract}
Objective: To investigate the impact of a pulmonary rehabilitation program on the functional capacity and on the quality of life of patients on waiting lists for lung transplantation. Methods: Patients on lung transplant waiting lists were referred to a pulmonary rehabilitation program consisting of 36 sessions. Before and after the program, participating patients were evaluated with the six-minute walk test and the Medical Outcomes Study 36-item Short-Form Health Survey (SF-36). The pulmonary rehabilitation program involved muscle strengthening exercises, aerobic training, clinical evaluation, psychiatric evaluation, nutritional counseling, social assistance, and educational lectures. Results: Of the 112 patients initially referred to the program, 58 completed it. The mean age of the participants was $46 \pm 14$ years, and females accounted for $52 \%$. Of those 58 patients, 37 (47\%) had pulmonary fibrosis, 13 (22\%) had pulmonary emphysema, and 18 (31\%) had other types of advanced lung disease. The six-minute walk distance was significantly greater after the program than before ( $439 \pm 114 \mathrm{~m}$ vs. $367 \pm 136 \mathrm{~m}, \mathrm{p}=0.001)$, the mean increase being $72 \mathrm{~m}$. There were significant point increases in the scores on the following SF-36 domains: physical functioning, up $22(p=0.001)$, role-physical, up 10 ( $p=0.045)$; vitality, up 10 ( $p<0.001)$; social functioning, up 15 ( $p=0.001)$; and mental health, up 8 $(p=0.001)$. Conclusions: Pulmonary rehabilitation had a positive impact on exercise capacity and quality of life in patients on lung transplant waiting lists.
\end{abstract}

Keywords: Rehabilitation; lung transplantation; Quality of life; Exercise; Exercise tolerance.

\section{Resumo}

Objetivo: Avaliar o impacto de um programa de reabilitação pulmonar na capacidade funcional e na qualidade de vida de pacientes em lista de espera para transplante pulmonar. Métodos: Pacientes em lista de espera para transplante pulmonar encaminhados a um programa de reabilitação pulmonar de 36 sessões. Os participantes foram avaliados no início e no final desse com o teste de caminhada de seis minutos (TC6) e com o questionário de qualidade de vida Medical Outcomes Study 36-item Short-Form Health Survey (SF-36). 0 programa de reabilitação pulmonar foi composto por exercícios de fortalecimento muscular, treinamento aeróbico, acompanhamento clínico e psiquiátrico, acompanhamento nutricional, assistência social e palestras educacionais. Resultados: Dos 112 pacientes encaminhados, 58 completaram o programa. A média de idade dos participantes foi de $46 \pm$ 14 anos; sendo 52\% do sexo feminino. Entre esses pacientes, 37 (47\%) eram portadores de fibrose pulmonar, 13 (22\%) tinham enfisema pulmonar, e 18 (31\%), tinham outras doenças pulmonares em fase avançada. Houve uma melhora significativa na distância percorrida no TC6 ao final do programa (367 \pm 136 m vs. $439 \pm 114$ m; $p=0,001)$, com um aumento médio de $72 \mathrm{~m}$. Houve aumentos significativos nas pontuações dos seguintes domínios do SF-36: capacidade funcional, 22 pontos ( $p=0,001)$; aspectos físicos, 10 ( $p=0,045)$; vitalidade, 10 ( $p<0,001)$; aspectos sociais, 15 ( $p=0,001)$; e saúde mental, 8 ( $p=0,001)$. Conclusões: 0 programa de reabilitação pulmonar teve um impacto positivo na capacidade de exercício e na qualidade de vida nos pacientes em lista de espera para transplante pulmonar.

Descritores: Reabilitação; Transplante de pulmão; Qualidade de vida; Exercício; Tolerância ao exercício.

\footnotetext{
* Study carried out in the Department of Pulmonary Rehabilitation and Physical Therapy, Santa Casa Sisters of Mercy Hospital Complex, Porto Alegre, Brazil.

Correspondence to: Juliessa Florian. Rua Professor Annes Dias, 295, CEP 90020-090, Porto Alegre, RS, Brasil.

Tel. 5551 3214-8331. E-mail: juliessaflorian@yahoo.com.br

Financial support: None.

Submitted: 3 September 2012. Accepted, after review: 25 April 2013.
} 


\section{Introduction}

Patients with advanced lung disease experience a dyspnea- and fatigue-related reduction in exercise tolerance. In recent decades, numerous strategies associated with pharmacological treatment have been studied to reduce symptoms and improve quality of life in these patients. ${ }^{(1)}$ Pulmonary rehabilitation, which is considered a non-pharmacological intervention with a high level of evidence (grade of recommendation $\mathrm{A}$ ) in the treatment of COPD, improves exercise tolerance and is fundamentally based on physical training, which, together with the other strategies, aims to relieve and control symptoms, minimize the complications of the disease, and help patients live an active life with few restrictions. ${ }^{(1-6)}$ Some studies have suggested that the benefits of a rehabilitation program are not associated with the stage of disease severity, and that rehabilitation should be recommended at any stage. ${ }^{(4-7)}$

For patients with advanced lung disease, lung transplantation is a treatment option that has contributed to improving quality of life and increasing survival. ${ }^{(8-10)}$ Recent studies have demonstrated the benefits that pulmonary rehabilitation can bring to patients after lung transplantation..$^{(8,11,12)}$ The benefits of rehabilitation in patients on lung transplant waiting lists are not yet conclusive, because previous studies have involved a small number of patients, heterogeneous samples, and different intervention protocols. Jastrzebski et al..$^{(9)}$ used the Medical Outcomes Study 36-item Short-Form Health Survey (SF-36) to assess quality of life in 16 waiting list patients with idiopathic pulmonary fibrosis and 14 waiting list patients with COPD at two time points: at the time of referral for lung transplantation and one year later. Those authors found that there was worsening in the role-physical domain, and that the patients with COPD had worse scores than did those with pulmonary fibrosis. Therefore, pre-transplant pulmonary rehabilitation is essential to minimize loss of functional performance while patients are awaiting transplantation. ${ }^{(13)}$

The hypothesis of the present study was that patients on lung transplant waiting lists who participate in an individualized, multidisciplinary pulmonary rehabilitation program would experience benefits in terms of both exercise tolerance and health-related quality of life. The objective of the present study was to analyze the impact of a pulmonary rehabilitation program on the functional capacity and quality of life of patients on lung transplant waiting lists.

\section{Methods}

This was a prospective study conducted in the Department of Pulmonary Rehabilitation of the Pereira Filho Ward, Department of Lung Diseases of the Santa Casa Hospital Complex in Porto Alegre, Porto Alegre, Brazil. The research project was approved by the Research Ethics Committee of the Santa Casa Hospital Complex in Porto Alegre. All patients gave written informed consent, agreeing to participate in the study.

Between June of 2007 and November of 2010, the study included patients with advanced lung disease who were undergoing optimized drug therapy and were placed on lung transplant waiting lists in accordance with the criteria established in the international guidelines for the selection of lung transplant candidates. ${ }^{(12)}$ Considering the broad base of evidence supporting the recommendation of pulmonary rehabilitation for patients with advanced lung disease, participation in rehabilitation is one of the criteria for remaining on waiting lists and is recommended by the lung transplant team of the Santa Casa Hospital Complex in Porto Alegre. The clinical information about the diagnosis was collected from the medical charts of the patients. The pulmonary function tests were performed in accordance with the technical procedures and the acceptability and reproducibility criteria of the American Thoracic Society/European Respiratory Society and the Brazilian Thoracic Association (BTA). ${ }^{(14-16)}$ The tests were performed in the pulmonary function laboratory of our institution, which is a laboratory certified by the BTA.

The pulmonary rehabilitation program involved the following steps: medical appointments with the transplant team every two months; psychiatric evaluations, nutritional counseling, social assistance, and monthly educational lectures.

The physical training was administered by two physical therapists. The sessions, each lasting 90 minutes, took place three times a week, totaling 36 meetings. The following activities were performed: warming-up, which consisted of breathing exercises (respiratory cycle) associated with arm raising; and muscle strengthening, which was based on arm and leg exercises with an initial load of 30\% of one repetition maximum testing and with one set of 10 repetitions per exercise. ${ }^{(17)}$ The load was increased by $0.5 \mathrm{~kg}$ every 7 sessions according 
to the patient tolerance. Aerobic exercises were performed on a treadmill (Inbrasport, Porto Alegre, Brazil), beginning at $60 \%$ of the speed of the patient on the six-minute walk test (6MWT), with a progressive protocol every 6 minutes for the variable time until reaching 30 minutes. The speed was increased by $0.3 \mathrm{~km} / \mathrm{h}$ every 7 sessions. The completion of all exercises was limited when the patient reported dyspnea or leg fatigue, indicated by a modified Borg scale score greater than 4 , and when the $\mathrm{SpO}_{2}$ reached $92 \%$. At the end of each session, stretching was performed for the major muscle groups involved. During the rehabilitation program, all patients received continuous oxygen therapy in accordance with the medical prescription and were constantly monitored by pulse oximetry. An oxygen flow required to maintain an $\mathrm{SpO}_{2} \geq 92 \%$ was used.

Before and after the 36 sessions, the patients were evaluated by the same physical therapists with the 6MWT, in accordance with the American Thoracic Society recommendations, and the SF-36. ${ }^{18-20)}$ The modified Borg scale was used for measuring dyspnea and leg discomfort. ${ }^{(21)}$

Data analysis was performed with the Statistical Package for the Social Sciences, version 14.0 (SPSS Inc, Chicago, IL, USA). Distribution of symmetrical variables was assessed by the Kolmogorov-Smirnov test. Continuous variables are expressed as mean and standard deviation or as median and interquartile range, whereas categorical variables are expressed as absolute and relative frequency.

The study outcomes before and after the rehabilitation sessions were compared with the Student's t-test for paired samples. The chi-square test was used for continuous variables, and the Mann-Whitney $U$ test was used for categorical variables. The level of significance was set at 5\%.

\section{Results}

During the study period, 112 patients were placed on lung transplant waiting lists and referred for pulmonary rehabilitation. Of those, $54 \mathrm{did}$ not complete the 36 sessions of the program and were excluded from the study. The reasons for not completing the rehabilitation program were as follows: having undergone lung transplantation before the end of the program, 43 patients; having died, 8 patients; having given up transplantation, 2 patients; and having been hospitalized for a long time, 1 patient (Figure 1). Table 1 shows the comparison of demographic and functional characteristics between the 58 patients (53.7\%) who completed the program and the 54 (47.3\%) who were excluded. The only variable for which there was a significant difference between the groups was age. The patients who underwent the entire program were, on average, 5 years younger than were those who were excluded.

The results obtained before and after the rehabilitation program for the 6MWT variables are shown in Table 2. After completion of the program, there was a mean increase of $72 \mathrm{~m}$ in the six-minute walk distance (6MWD), and there was a significant decrease in perceived dyspnea. Resting and post-exercise $\mathrm{SpO}_{2}$ remained similar after the program, there being no statistically significant difference. The patients walked a greater distance and did not have greater desaturation because of the increased effort, reporting a lesser degree of dyspnea after the rehabilitation program. There was no difference in perceived leg fatigue at rest before and after the sessions; however, after completion of the program, the patients reported less discomfort, this difference being statistically significant.

There were significant point increases in the scores on the following SF-36 domains: physical functioning, up $22(p=0.001)$, rolephysical, up 10 ( $p=0.045)$; vitality, up $10(p<$ $0.001)$; social functioning, up $15(p=0.001)$; and mental health, up $8(p=0.001)$. No statistically significant differences were found for the other domains (Table 3).

\section{Discussion}

In the present study, lung transplant candidates who participated in an individualized, multidisciplinary pulmonary rehabilitation program showed significant clinical improvement in the 6MWT and in quality of life. The mean increase of $72 \mathrm{~m}$ in the 6MWD and the increase in the SF-36 physical functioning, role-physical, vitality, social functioning, and mental health domain scores, both of which observed after 36 sessions of aerobic exercise training and muscle strengthening, emphasize that pulmonary rehabilitation provides overall benefits to the health of this population.

The benefits of pulmonary rehabilitation in patients with COPD and pulmonary fibrosis have been well documented. ${ }^{(6,21,22)}$ In patients with COPD, rehabilitation has proven to improve exercise tolerance, to reduce dyspnea, to improve 


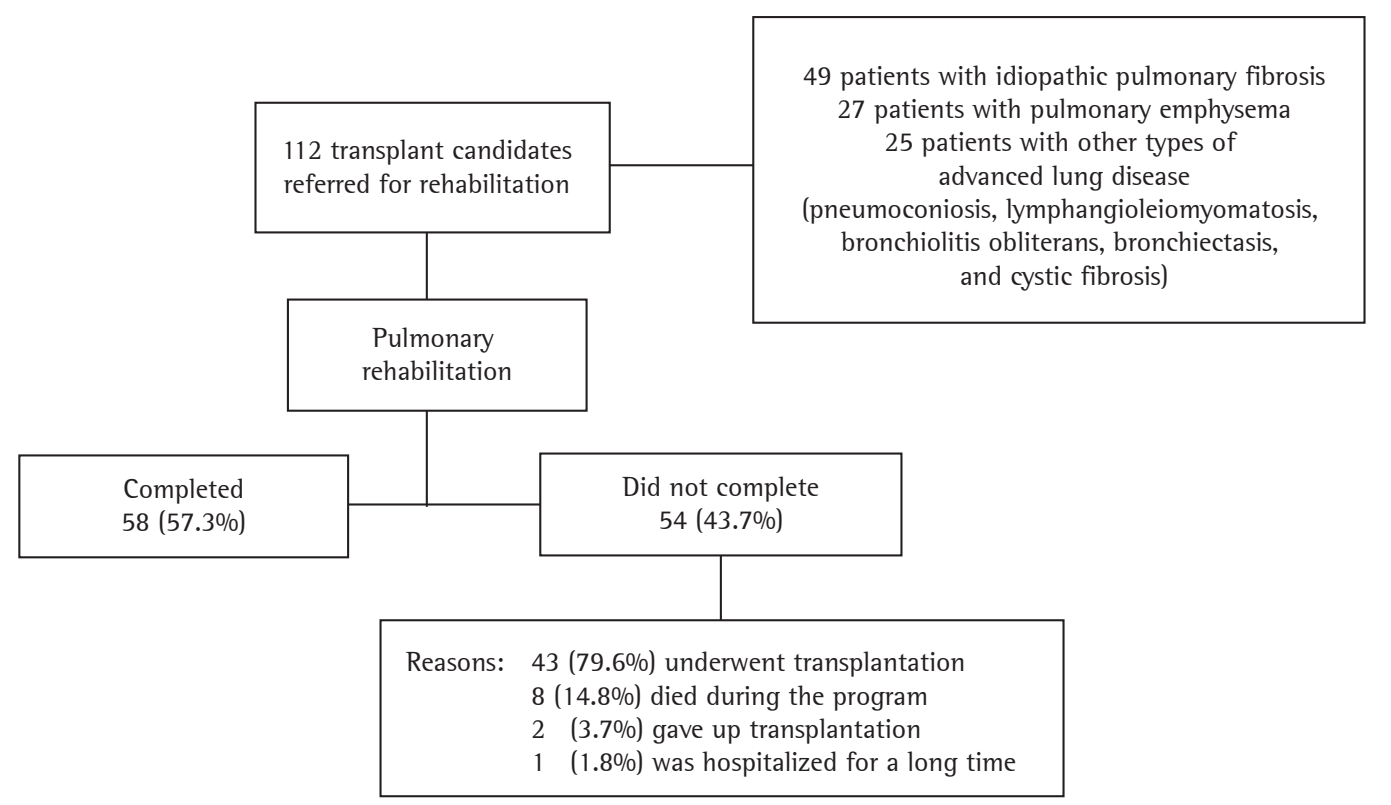

Figure 1 - Flowchart of patient inclusion in the study.

Table 1 - Baseline characteristics of the sample of lung transplant candidates who were prescribed the pulmonary rehabilitation program. ${ }^{\text {a }}$

\begin{tabular}{|c|c|c|c|}
\hline Variable & Participants & Non-participants & $\mathrm{p}$ \\
\hline & $(\mathrm{n}=58)$ & $(n=54)$ & \\
\hline \multicolumn{4}{|l|}{ Demography } \\
\hline Male gender, n (\%) & $28(48)$ & $27(63)$ & 0.163 \\
\hline Age, years & $46 \pm 14$ & $51 \pm 11$ & $<0.001$ \\
\hline \multicolumn{4}{|l|}{ Anthropometry } \\
\hline BMl, $\mathrm{kg} / \mathrm{m}^{2}$ & $23 \pm 4$ & $24 \pm 3$ & 0.162 \\
\hline \multicolumn{4}{|l|}{ Diagnosis, n (\%) } \\
\hline Idiopathic pulmonary fibrosis & $27(47)$ & $22(51)$ & 0.199 \\
\hline Pulmonary emphysema & $13(22)$ & $14(32)$ & \\
\hline Others ${ }^{\mathrm{b}}$ & $18(31)$ & $7(16)$ & \\
\hline \multicolumn{4}{|l|}{ Pulmonary function ${ }^{c}$} \\
\hline FVC, L & $1.12 \pm 0.6$ & $0.95 \pm 0.4$ & 0.172 \\
\hline FVC, \% of predicted & $44.9 \pm 16.5$ & $41.1 \pm 11.3$ & 0.194 \\
\hline $\mathrm{FEV}_{1}, \mathrm{~L}$ & $0.43 \pm 0.62$ & $0.39 \pm 0.49$ & 0.853 \\
\hline $\mathrm{FEV}_{1}, \%$ of predicted & $32.9 \pm 15.9$ & $31.6 \pm 16.8$ & 0.695 \\
\hline $\mathrm{FEV}_{1} / \mathrm{FVC}$ & $0.44 \pm 0.49$ & $0.34 \pm 0.44$ & 0.316 \\
\hline \multicolumn{4}{|l|}{ 6MWT } \\
\hline 6MWD, m & $367 \pm 136$ & $330 \pm 135$ & 0.992 \\
\hline $6 \mathrm{MWD}, \%$ of predicted & $56.6 \pm 22.6$ & $48.7 \pm 24.8$ & 0.082 \\
\hline PASP, $\mathrm{mmHg}$ & $44.8 \pm 17.3$ & $42.9 \pm 17.1$ & 0.580 \\
\hline
\end{tabular}

BMI: body mass index; 6MWT: six-minute walk test; 6MWD: six-minute walk distance; and PASP: pulmonary artery systolic pressure. ${ }^{a}$ Values expressed as mean $\pm \mathrm{SD}$, except where otherwise indicated. ${ }^{b}$ Lymphangioleiomyomatosis, bronchiolitis obliterans, and pneumoconiosis. 'Post-bronchodilator pulmonary function tests.

quality of life, and to reduce the use of health resources. As adjuvant treatment to surgical programs, such as lung volume reduction surgery, rehabilitation plays an important role in the preparation of these patients for the procedure, facilitating postoperative recovery. ${ }^{(1,23)}$

In the present study, most patients had pulmonary fibrosis and emphysema. In a study 
Impact of pulmonary rehabilitation on quality of life and functional capacity in patients on waiting lists for lung transplantation

Table 2 - Comparison of the six-minute walk test variables before and after the pulmonary rehabilitation program $(\mathrm{n}=58) .^{\mathrm{a}}$

\begin{tabular}{|c|c|c|c|c|}
\hline \multirow[t]{2}{*}{ Variable } & \multicolumn{3}{|c|}{ Pulmonary rehabilitation program } & \multirow[t]{2}{*}{$\mathrm{p}$} \\
\hline & Before & After & $\Delta^{\mathrm{b}}$ & \\
\hline 6MWD, m & $367 \pm 136$ & $439 \pm 114$ & $72(50-95)$ & 0.001 \\
\hline 6MWD, \% of predicted & $56,6 \pm 22,6$ & $75,5 \pm 16,6$ & $19(58-92)$ & 0.001 \\
\hline Resting $\mathrm{SpO}_{2}, \%$ & $95 \pm 2$ & $94 \pm 3$ & $2(1-2)$ & 0.001 \\
\hline Post-exercise $\mathrm{SpO}_{2}, \%$ & $80 \pm 9$ & $80 \pm 9$ & $0(-2$ to 2$)$ & 0.940 \\
\hline \multicolumn{5}{|l|}{ Modified Borg scale } \\
\hline Resting dyspnea & $0(0-2)^{c}$ & $0(0-0)^{c}$ & $-1(-1$ to 0$)$ & 0.001 \\
\hline Post-exercise dyspnea & $5(3-7)^{c}$ & $4(3-5)^{c}$ & $-1(-2$ to 0$)$ & 0.001 \\
\hline Leg fatigue at rest & $0(0-0)^{c}$ & $0(0-0)^{c}$ & $0(0-0)$ & 0.129 \\
\hline Leg fatigue after exercise & $3(0-5)^{c}$ & $2(0-3)^{c}$ & $-1(-2$ to 0$)$ & 0.011 \\
\hline
\end{tabular}

$\Delta$ : variation (measurement after the rehabilitation program - measurement before the rehabilitation program); and 6MWD: six-minute walk distance. ${ }^{a}$ Values expressed as mean $\pm \mathrm{SD}$, except where otherwise indicated. ${ }^{\text {b}}$ Values expressed as mean $(95 \% \mathrm{Cl})$. 'Values expressed as median (interquartile range).

Table 3 - Comparison of the domains of the Medical Outcomes Study 36-item Short-Form Health Survey (SF-36) before and after the pulmonary rehabilitation program $(\mathrm{n}=58){ }^{\text {a }}$

\begin{tabular}{lcccc}
\hline \multicolumn{1}{c}{ Variable } & \multicolumn{2}{c}{ Pulmonary rehabilitation program } & \multirow{2}{*}{$\mathrm{p}$} \\
\cline { 2 - 4 } & Before & After & \multicolumn{1}{c}{$\Delta^{\mathrm{b}}$} & $<0.001$ \\
Physical functioning & $20(10-35)$ & $45(30-55)$ & $22(17-26)$ & 0.045 \\
Role-physical & $0(0-25)$ & $06(0-50)$ & $10(1-19)$ & 0.055 \\
Bodily pain & $62(41-90)$ & $74(51-9)$ & $6(-1$ to 14$)$ & 0.151 \\
General health & $30(20-52)$ & $36(22-52)$ & $4(-2$ to 9$)$ & $<0.001$ \\
Vitality & $57(38-75)$ & $65(53-81)$ & $10(5-14)$ & $<0.001$ \\
Social functioning & $50(25-75)$ & $64(50-87)$ & $15(8-21)$ & 0.087 \\
Role-emotional & $33(0-100)$ & $66(0-100)$ & $12(-1$ to 25$)$ & 0.001 \\
Mental health & $82(64-88)$ & $84(79-92)$ & $8(4-13)$ & \\
\hline
\end{tabular}

$\Delta$ : variation (measurement after the rehabilitation program - measurement before the rehabilitation program). ${ }^{\text {aValues }}$ expressed as median (interquartile range), except where otherwise indicated. b Values expressed as mean $(95 \% \mathrm{Cl})$.

in which 30 patients with idiopathic pulmonary fibrosis were compared with 15 control group patients who did not undergo rehabilitation, those who underwent pulmonary rehabilitation obtained an increase of $46.3 \mathrm{~m}(95 \% \mathrm{Cl}: 8.3-84.4 ; \mathrm{p}<0.05)$ in the 6MWD. ${ }^{(24)} \mathrm{A}$ study involving 13 patients with idiopathic pulmonary fibrosis showed that, after a pulmonary rehabilitation program, there was a reduction in perceived dyspnea, as measured by the Borg scale, from $3.0 \pm 1.4$ to $2.5 \pm 1.4$ ( $p<$ 0.01). ${ }^{(25)}$ Although, in the present study, we did not analyze the underlying diseases separately, we found a significant improvement in the functional capacity and quality of life of the patients who completed the rehabilitation program.

In a prospective cohort study involving 376 patients on lung transplant waiting lists, the baseline 6MWD was analyzed as a predictor of survival in that population. Those authors found that post-transplant survival increased significantly as the 6MWD values increased in comparison with baseline values. In addition, they found that this relationship is similar in all types of lung disease; this reveals the possibility that rehabilitation programs in the pre-transplant phase can provide a favorable impact during hospitalization. The patients in the present study had a higher mean 6MWD after the rehabilitation program, which allows us to infer a higher probability of posttransplant survival. ${ }^{(26,27)}$

All of our patients underwent continuous training on a treadmill, i.e., a conventional program. A randomized clinical trial investigated different modes of exercise (interval vs. continuous) in lung transplant candidates and found that there was an increase in the 6MWD in the two groups studied, with a greater reduction in dyspnea occurring in the group receiving interval training. (13) In another study, a different mode of training, i.e., Nordic walking with ski poles, was used for twelve weeks in a pulmonary rehabilitation program in lung transplant candidates. Those 
authors observed a significant increase in mean 6MWD (310.2 m vs. $372.1 \mathrm{~m} ; \mathrm{p}<0.05)$ and improvement in the SF-36 social functioning domain ( $p<0.05$ ), demonstrating that the type of training was safe and feasible. ${ }^{(28)}$

Most of the current pulmonary rehabilitation programs, designed for lung transplant candidates, comply with the general recommendations for pulmonary rehabilitation, with a weekly frequency of two to three sessions per week, over a period of six to eight weeks. These programs include aerobic training, arm and leg muscle strengthening, and also an educational component, which, in addition to the aspects of the disease that are commonly addressed, needs to include issues relevant to the procedure itself, educating patients regarding immunosuppressive drugs, rejection, infections, and complications so that they can adopt a new lifestyle. . $^{(1,3,11,25)}$

Considering that, of the 112 patients referred to our program, most completed it, it should be emphasized that many of the excluded patients from the analysis were excluded because they underwent transplantation. The excellent adherence to the program in our study population can be explained by the fact that pulmonary rehabilitation is included in the preoperative treatment plan for this group of patients who are highly motivated for surgery. Patients who are preparing for lung transplantation represent a selected group of individuals with advanced chronic respiratory disease and often remain on waiting lists for long periods of time. Since maintaining health status, exercise capacity, and quality of life are key factors for a highly complex surgical procedure, ongoing maintenance of these patients in a rehabilitation program would be a desirable strategy. ${ }^{(11,25,27)} \mathrm{In}$ this context, a determining factor in the success of rehabilitation programs would be patient adherence to scheduled sessions. ${ }^{(4)}$ A study involving 711 patients referred for pulmonary rehabilitation demonstrated that $31.8 \%$ of those patients did not attend the programs and that, of those who did, 29.1\% were non-adherent. Using a logistic regression model, those researchers observed that use of long-term oxygen therapy and living alone were independent factors for non-attendance. In addition, being a current smoker, performing poorly on the shuttle test, and hospitalizations were independent predictors of poor adherence. ${ }^{(29)}$
Since this group of patients is only one of the several groups that use pulmonary rehabilitation, we have established a rotation strategy for those remaining on waiting lists for long periods of time. This strategy, which provides access to rehabilitation opportunities for all, was based on a study in which the authors concluded that the benefits of a rehabilitation program on the indices of anxiety, depression, quality of life, and exercise capacity persisted over 24 months in patients with COPD. ${ }^{(30)}$

Among the limitations of our study is the lack of a control group, the use of which was considered by us, in the preparation of the protocol, to be an unethical strategy, given that various studies have emphasized the importance of rehabilitation in advanced lung disease. The fact that cardiopulmonary exercise testing was not used might have underestimated the training strategy of these patients, preventing them from further improving their exercise capacity. Another factor that can be considered a limitation is the lack of an analysis of the emotional aspects of these patients, who view transplantation as their last chance of improving their disease outcome.

The findings of the present study allow us to conclude that the individualized, multidisciplinary pulmonary rehabilitation program was beneficial for patients on lung transplant waiting lists. The patients who participated in the program showed significant clinical improvement after 36 physical training sessions, as well as showing improvement in the 6MWD and in quality of life, which underscores the need for rehabilitation programs at facilities performing complex surgical procedures, such as lung transplantation.

\section{References}

1. Ries AL, Bauldoff GS, Carlin BW, Casaburi R, Emery CF, Mahler DA, et al. Pulmonary Rehabilitation: Joint ACCP/AACVPR Evidence-Based Clinical Practice Guidelines. Chest. 2007;131(5 Suppl):4S-42S. http:// dx.doi.org/10.1378/chest.06-2418 PMid:17494825

2. Sabit R, Griffiths TL, Watkins AJ, Evans W, Bolton CE, Shale DJ, et al. Predictors of poor attendance at an outpatient pulmonary rehabilitation programme. Respir Med. 2008;102(6):819-24. http://dx.doi.org/10.1016/j. rmed.2008.01.019 PMid:18337077

3. Nici L, Donner C, Wouters E, Zuwallack R, Ambrosino $\mathrm{N}$, Bourbeau J, et al. American Thoracic Society/ European Respiratory Society statement on pulmonary rehabilitation. Am J Respir Crit Care Med. 
2006;173(12):1390-413. http://dx.doi.org/10.1164/ rccm.200508-1211ST PMid:16760357

4. Garrod R, Malerba M, Crisafulli E. Determinants of success. Eur Respir J. 2011;38(5):1215-8. http://dx.doi. org/10.1183/09031936.00088611 PMid:22045787

5. Wijkstra PJ, Wempe JB. New tools in pulmonary rehabilitation. Eur Respir J. 2011;38(6):1468-74. http:// dx.doi.org/10.1183/09031936.00111911 PMid:21828026

6. Evans RA, Singh SJ, Collier R, Williams JE, Morgan MD. Pulmonary rehabilitation is successful for COPD irrespective of MRC dyspnoea grade. Respir Med. 2009;103(7):1070-5. http://dx.doi.org/10.1016/j. rmed.2009.01.009 PMid:19217765

7. Ihle F, Neurohr C, Huppmann P, Zimmermann G, Leuchte $\mathrm{H}$, Baumgartner R, et al. Effect of inpatient rehabilitation on quality of life and exercise capacity in long-term lung transplant survivors: a prospective, randomized study. J Heart Lung Transplant. 2011;30(8):912-9. PMid:21489819

8. Lahzami S, Nicod LP. Inhaled therapies for cystic fibrosis [Article in French]. Rev Med Suisse. 2011;7(318):2285-8. PMid:22400363

9. Jastrzebski D, Gumola A, Gawlik R, Kozielski J. Dyspnea and quality of life in patients with pulmonary fibrosis after six weeks of respiratory rehabilitation. J Physiol Pharmacol. 2006;57 Suppl 4:139-48. PMid:17072040

10. Aurora P, Boucek MM, Christie J, Dobbels F, Edwards LB, Keck BM, et al. Registry of the International Society for Heart and Lung Transplantation: tenth official pediatric lung and heart/lung transplantation report--2007. J Heart Lung Transplant. 2007;26(12):1223-8. http:// dx.doi.org/10.1016/j.healun.2007.07.035 PMid:18096472

11. Rochester CL. Pulmonary rehabilitation for patients who undergo lung-volume-reduction surgery or lung transplantation. Respir Care. 2008;53(9):1196-202. PMid:18718039

12. Orens JB, Estenne M, Arcasoy S, Conte JV, Corris P, Egan $\mathrm{JJ}$, et al. International guidelines for the selection of lung transplant candidates: 2006 update--a consensus report from the Pulmonary Scientific Council of the International Society for Heart and Lung Transplantation. J Heart Lung Transplant. 2006;25(7):745-55. http:// dx.doi.org/10.1016/j.healun.2006.03.011 PMid:16818116

13. Gloeckl R, Halle M, Kenn K. Interval versus continuous training in lung transplant candidates: a randomized trial. J Heart Lung Transplant. 2012;31(9):934-41. http:// dx.doi.org/10.1016/j.healun.2012.06.004 PMid:22884381

14. Miller MR, Hankinson J, Brusasco V, Burgos F, Casaburi R, Coates A, et al. Standardisation of spirometry. Eur Respir J. 2005;26(2):319-38. http://dx.doi.org/10.118 3/09031936.05.00034805 PMid:16055882

15. Macintyre N, Crapo RO, Viegi G, Johnson DC, van der Grinten CP, Brusasco V, et al. Standardisation of the single-breath determination of carbon monoxide uptake in the lung. Eur Respir J. 2005;26(4):720-35. http://dx.doi. org/10.1183/09031936.05.00034905 PMid:16204605

16. Sociedade Brasileira de Pneumologia. Diretrizes para Testes de Função Pulmonar. J Pneumol. 2002;28(3):1-238.

17. Barnard KL, Adams KJ, Swank AM, Mann E, Denny DM. Injuries and muscle soreness during the one repetition maximum assessment in a cardiac rehabilitation population. J Cardiopulm Rehabil. 1999;19(1):52-8. http://dx.doi. org/10.1097/00008483-199901000-00007 PMid:10079421
18. ATS Committee on Proficiency Standards for Clinical Pulmonary Function Laboratories. ATS statement: guidelines for the six-minute walk test. Am J Respir Crit Care Med. 2002;166(1):111-7. http://dx.doi.org/10.1164/ ajrccm.166.1.at1102 PMid:12091180

19. Campolina AG, Ciconelli RM. SF-36 and the development of new assessment tools for quality of life [Article in Portuguese]. Acta Reumatol Port. 2008;33(2):127-33. PMid:18604180

20. Enright PL, Sherrill DL. Reference equations for the six-minute walk in healthy adults. Am J Respir Crit Care Med. 1998;158(5 Pt 1):1384-7. http://dx.doi.org/10.1164/ ajrccm.158.5.9710086 PMid:9817683

21. Mador MJ, Rodis A, Magalang UJ. Reproducibility of Borg scale measurements of dyspnea during exercise in patients with COPD. Chest. 1995;107(6):1590-7. http:// dx.doi.org/10.1378/chest.107.6.1590 PMid:7781352

22. Puhan MA, Mador MJ, Held U, Goldstein R, Guyatt $\mathrm{GH}$, Schünemann HJ. Interpretation of treatment changes in 6-minute walk distance in patients with COPD. Eur Respir J. 2008;32(3):637-43. http://dx.doi. org/10.1183/09031936.00140507 PMid:18550610

23. Case-Smith J, Holland T. Making decisions about service delivery in early childhood programs. Lang Speech Hear Serv Sch. 2009;40(4):416-23. http://dx.doi. org/10.1044/0161-1461(2009/08-0023)

24. Nishiyama O, Kondoh Y, Kimura T, Kato K, Kataoka K, Ogawa $\mathrm{T}$, et al. Effects of pulmonary rehabilitation in patients with idiopathic pulmonary fibrosis. Respirology. 2008;13(3):394-9. http://dx.doi.org/10.1111/j.14401843.2007.01205.x PMid:18399862

25. Holland AE, Hill CJ, Glaspole I, Goh N, McDonald CF. Predictors of benefit following pulmonary rehabilitation for interstitial lung disease. Respir Med. 2012;106(3):42935. http://dx.doi.org/10.1016/j.rmed.2011.11.014 PMid:22182340

26. Martinu T, Babyak MA, O'Connell CF, Carney RM, Trulock EP, Davis RD, et al. Baseline 6-min walk distance predicts survival in lung transplant candidates. Am J Transplant. 2008;8(7):1498-505. http://dx.doi.org/10.1111/j.16006143.2008.02264.x PMid:18510641 PMCid:2714545

27. Wickerson L, Mathur S, Brooks D. Exercise training after lung transplantation: a systematic review. J Heart Lung Transplant. 2010;29(5):497-503. http://dx.doi. org/10.1016/j.healun.2009.12.008 PMid:20133160

28. Jastrzebski D, Ochman M, Ziora D, Labus L, Kowalski $\mathrm{K}$, Wyrwol J, et al. Pulmonary rehabilitation in patients referred for lung transplantation. Adv Exp Med Biol. 2013;755:19-25. http://dx.doi.org/10.1007/978-94007-4546-9_3 PMid:22826045

29. Hayton C, Clark A, Olive S, Browne P, Galey P, Knights E, et al. Barriers to pulmonary rehabilitation: characteristics that predict patient attendance and adherence. Respir Med. 2013;107(3):401-7. http://dx.doi.org/10.1016/j. rmed.2012.11.016 PMid:23261311

30. Godoy RF, Teixeira PJ, Becker Júnior B, Michelli M, Godoy DV. Long-term repercussions of a pulmonary rehabilitation program on the indices of anxiety, depression, quality of life and physical performance in patients with COPD. J Bras Pneumol. 2009;35(2):129-36. PMid:19287915 


\section{About the authors}

\section{Juliessa Florian}

Physical Therapist in Charge. Department of Pulmonary Rehabilitation and Physical Therapy, Santa Casa Sisters of Mercy Hospital Complex, Porto Alegre, Brazil.

\section{Adalberto Rubin}

Adjunct Professor of Pulmonology. Universidade Federal de Ciências da Saúde de Porto Alegre - UFSCPA, Federal University of Health Sciences of Porto Alegre - Porto Alegre, Brazil.

\section{Rita Mattiello}

Adjunct Professor. Pontifícia Universidade Católica do Rio Grande do Sul - PUCRS, Pontifical Catholic University of Rio Grande do Sul - School of Medicine, Porto Alegre, Brazil.

\section{Fabrício Farias da Fontoura}

Physical Therapist. Department of Pulmonary Rehabilitation and Physical Therapy, Santa Casa Sisters of Mercy Hospital Complex, Porto Alegre, Brazil.

\section{José de Jesus Peixoto Camargo}

Professor of Thoracic Surgery. Universidade Federal de Ciências da Saúde de Porto Alegre - UFSCPA, Federal University of Health Sciences of Porto Alegre - and Medical Director. Transplant Center, Dom Vicente Scherer Hospital, Porto Alegre, Brazil.

\section{Paulo Jose Zimermann Teixeira}

Adjunct Professor of Pulmonology, Universidade Federal de Ciências da Saúde de Porto Alegre - UFSCPA, Federal University of Health Sciences of Porto Alegre - and Full Professor. Feevale University, Novo Hamburgo, Brazil. 